\title{
Psychiatry in Turkey
}

\author{
Armagan Y. Samanci and Husnu Erkmen
}

The first recorded notes regarding mental lllness and mental health care can be found in the books of Avicenna, a prominent Anatolian doctor and scientist (980-1037). It is known that villages serving as asylums existed in Anatolia in those days. Later, small asylums were built beside the mosques which generally contained educational and charitable units. There were 12 small mosque asylums in Istanbul alone, the largest caring for $\mathbf{5 0}$ mentally disordered.

During World War I, Toptası Asylum served the mentally ill but the unacceptable conditions there led to its closure. The establishment of Bakurkoy Asylum was a consequence of the closure which, in time, was followed by the emergence of other mental health units throughout the country.

At present, there are 86 hospitals with psychiatric units and a total of $\mathbf{4 3 9}$ psychiatrists in Turkey. Six hospitals, including Bakirkoy, are built solely for mental health purposes. Those hospitals represent $71.9 \%$ of all Turkish psychiatric beds and the rest are divided between government and university hospitals (Onder \& Sahun, 1993). Some hospitals have psychiatric units serving only as out-patient departments.

Patients' expenses are covered by national health insurance if they are in the scheme. Up to $30 \%$ of the population are not covered under any health insurance scheme. Those unable to pay are offered the government subsidised green card scheme which pays for them. The remaining population receive their private health insurance or pay for themselves.

Bakurkoy Psychiatric Hospital, formerly Bakurkoy Asylum, has as important place in Turkish psychiatry today, as it contains 2185 psychiatric beds. The number of senior doctors in the hospital are 66 and trainees 99 . In relation to the total number of Turkish psychiatric trainees, Bakurkoy provides the majority of qualified Turkish psychiatrists.

The hospital has gone through a number of radical changes. In 1979, as a result of severe criticism of the conditions there, the hospital was structurally renovated and new services opened. An alcohol and drug addiction unit was set up in 1987, followed by neurosis and forensic psychiatry departments. There are occupational therapy and rehabilitation units though these units do not fulfil their proper function. Psy- chiatric units are divided between acute admission and longstay wards which have lower standards of care.

Besides the psychiatric units, the hospital has a neurology department, a neurosurgery department, a radiology department, a computerised axial tomography unit, a health centre and a dental unit.

\section{Training}

Turkish medical school graduates have to take TUS (a postgraduate general medicine examination) to be accepted for a postgraduate training scheme. The psychiatric trainees pass this highly competitive general examination and are automatically enrolled into the training scheme at the hospital they choose.

The scheme runs for four years. The hospital is a recognised training hospital and publishes a yearly book for its training programme. Each department designs its training programme and this goes through the hospital's training and education council before it is implemented.

Each year trainees join unit training sessions together. There is an active training commitment in the hospital and case presentations and conferences are held regularly. The hospital invites lecturers from the other training hospitals. Bakurkoy is also visited and lectured to by foreign psychiatrists and scientists throughout the year.

The trainees spend the first 15 months in acute admission wards for psychotic patients, six months in the neurosis department, three months in the forensic psychiatry unit and three months in the drug and alcohol addiction unit. Additionally, they rotate with nine months in neurology, three months in general medicine and three months in a child psychiatry unit.

The remaining time is spent in their attached unit. The trainee has to complete a thesis before being eligible to take a board examination. After passing the examination, in which the trainee presents a case and is questioned about the case and his knowledge, he is awarded a specialist qualification by the Ministry of Health.

\section{Problems}

The hospital, until the last decade, served mostly psychotically ill patients and still admits most of 
these patients if they cannot be contained in the small-scale hospital units. Therefore the hospital is heavily burdened. Medical therapy methods are overemployed. Premature discharges are common in order to make avallable beds for new admissions.

The trainees most frequently see psychotic patients and their approach to other patients is heavily influenced by this experience. The training in the neurosis department, in which they are exposed to what they would probably see in their out-patient departments in the district hospitals, falls short of providing a broad experience in psychiatry.

Community psychiatry is virtually nonexistent in Turkey and the concept of rehabilitation has hardly been comprehended. This leaves psychiatry with hospital-based treatment methods. There are no effective follow-up services for discharged patients who are lost if they do not come to the out-patient clinic.

Patients' needs and care are not taken into account after discharge. Funding has not been allocated for care systems outside hospital.

Training is based heavily on biological psychiatry and pharmacological therapy prevails. ECT is used widely in some hospital units, frequently for schizophrenia and a large spectrum of affective disorders. Psychotherapy is gradually becoming popular among younger trainees. Consequently, psychological treatment methods and training in them are highly demanded.

Turkish nurses are trained for general nursing purposes. Unfortunately, there is no psychiatric nursing school. This deprives the profession of an essential component.

Turkey has not yet developed a Mental Health Act. The Ministry recently circulated a draft Act but it may take some time to come into effect.

The hospital has recently founded a research ethics committee and clinical ethics have been gaining increasing importance.

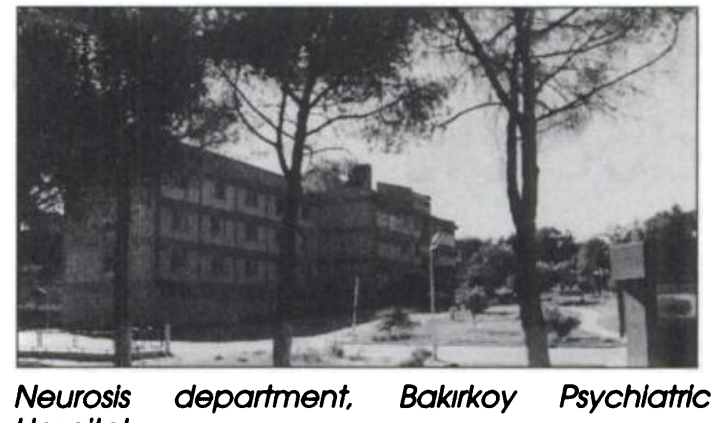

Hospital

Turkish psychiatry is progressing towards contemporary psychiatric care. The need for modern psychiatric services has suddenly emerged at the same time as socio-cultural changes in society. The present services are not adequate and do not serve the target population. Reorganisation and restructuring of services towards community based mental health services might be much easier to achieve than in Western societies as the majority of the mentally ill already live in the community with their families due to lack of residential care units. However, present health care policies fall to take account of this important issue.

\section{References}

ONDER, M.E. \& SAHIN, A.R. (1993) Current status of psychiatry in Turkey. Journal of Psychiatry. Psychology and Psychopharmacology, 1, 64-71.

Armagan Y. Samanci, Sentor Registrar in Psychiatry; and Husnu Erkmen, Consultant Psychiatrist, Bakirkoy Psychiatric Hospital, Bakurkoy, Istanbul 34747

\section{Invitation for articles from overseas}

We invite Members of the College outside the UK and Ireland to submit articles for consideration for publication in the Psychiatric Bulletin. We are particularly interested to learn about developments in psychiatric care in their countries, or localities, or learning about the particular pleasures or challenges of practising psychiatry where they work.

ALAN KERR, Editor, Psychiatric Bulletin 